\title{
NUEVOS HOSPEDEROS Y REGISTROS DE ÁCAROS FITÓFAGOS PARA COSTA RICA: PERÍODO 2013-2018
}

\author{
Hugo Aguilar-Piedra ${ }^{1 / *}$, Ana María Solano-Guevara ${ }^{2}$ \\ Palabras clave: Acari; ácaros fitófagos; Eotetranychus; Oligonychus; Tetranychus; \\ Polyphagotarsonemus; Costa Rica. \\ Keywords: Acari; plant feeding mites; Eotetranychus; Oligonychus; Tetranychus; \\ Polyphagotarsonemus; Costa Rica.
}

Recibido: 08/02/19

Aceptado: $12 / 06 / 19$

RESUMEN

Las especies de ácaros fitófagos identificadas para Costa Rica no han sido actualizadas desde el 2013, por lo que se procedió a resumir la información disponible del 2013 al 2018 e incorporarla a la existente. El material procesado fue suministrado por personas productoras, técnicas, estudiantes y público en general, en conjunto con el recolectado por el personal del Laboratorio de Acarología de la Universidad de Costas Rica, con el uso de los protocolos desarrollados para tal fin. Setenta y cinco nuevos registros de ácaros fitófagos fueron consignados para ese período, agrupados en 30 familias de plantas para las 6 familias de ácaros fitófagos que revisten más trascendencia. Tetranychus urticae, de la familia Tetranychidae, fue la especie con mayor número de registros, para un total de 24. Diversas especies del género Oligonychus fueron encontradas con frecuencia en varias plantas hospedantes, i.e. O. gossypii, O. mcgregori, O. punicae, O. yothersi y O. zeae. Otros

\footnotetext{
* Autor para correspondencia. Correo electrónico: hugo.aguilar@ucr.ac.cr

1 Universidad de Costa Rica, Museo de Insectos, CIPROC, San José, Costa Rica. (D) 0000-0003-3335-7439.
}

New hosts and records of plant feeding mites for Costa Rica: interval 2013-2018. The species of phytophagous mites identified for Costa Rica have not been updated since 2013, so the list was summarized by using the information available from 2013 to 2018 and incorporated into the existing one. The processed material was supplied by growers, technicians, students, and public in general, besides the material collected by the Laboratory of Acarology personnel, from the University of Costa Rica, by using the protocols developed for that matter. Seventy five new entries were introduced for this period, grouped in 30 plant families, for the 6 major phytophagous mite families. Tetranychus urticae, family Tetranychidae, was the species with the highest number of introductions, 24 in total. Various species in the genus Oligonychus were often found on a diverse number of host plants, i.e. O. gossypii, O. mcgregori, O. punicae, $O$. yothersi, and $O$. zeae. Other spider mites collected

2 Universidad de Costa Rica, Museo de Insectos, CIPROC, San José, Costa Rica. (iD) 0000-0002-2975-1241. 
tetraníquidos recolectados fueron Eotetranychus deleoni, Mononychellus sp., Panonychus citri, Schizotetranychus sp., Tetranychus cinnabarinus, T. mexicanus y T. turkestani. Brevipalpus papayensis, B. phoenicis y B. yothersi, de la familia Tenuipalpidae; de igual manera, fueron recolectados en nuevas plantas hospedantes. Asimismo, Tuckerella ornata, de la familia Tuckerellidae, fue registrada junto con otra especie todavía no identificada. Se presentaron 4 nuevos registros para Polyphagotarsonemus latus, de la familia Tarsonemidae y una nueva variedad de fresa infestada con Phytonemus pallidus. Las especies de ácaros de la familia Eriophyidae fueron agrupadas como expuestas y no expuestas porque, con seguridad, son especies no descritas aún. Se hizo la corrección para Retracrus costaricensis, de Heliconia latispatha, que fue registrado como $R$. johnstoni en el 2012. Se elaboró una descripción de síntomas para algunas de las especies más relevantes, apoyada con fotografías de los daños. En consecuencia, el reconocimiento de las especies de ácaros fitófagos en Costa Rica, se mantiene al día hasta el año 2018.

\section{INTRODUCCIÓN}

Parte de las actividades del Laboratorio de Acarología del Centro de Investigación en Protección de Cultivos (CIPROC), de la Escuela de Agronomía, Facultad de Ciencias Agroalimentarias de la Universidad de Costa Rica, es llevar a cabo muestreos periódicos cada año para registrar los ácaros fitófagos que se encuentran asociados con cultivos, así como con malas hierbas u otras plantas. Además, de las recolectas realizadas por el personal del laboratorio, se recibe y analiza material traído por personas productoras, estudiantes, etc.

Es así como, desde la apertura de la Clínica de Diagnóstico de Ácaros en el 2002, se han mantenido registros de interés para personas were Eotetranychus deleoni, Mononychellus sp., Panonychus citri, Schizotetranychus sp., Tetranychus cinnabarinus, T. mexicanus, and T. turkestani. Brevipalpus papayensis, B. phoenicis and $B$. yothersi, family Tenuipalpidae, were also collected on new host plants. Likewise, Tuckerella ornata, family Tuckerellidae, was registered, as well as another species, not identified yet. From the family Tarsonemidae, four new entries for Polyphagotarsonemus latus were included, as well as one for Phytonemus pallidus, found on a new variety of strawberry. Species from the family Eriophyidae were grouped as exposed and not exposed individuals due to most of eriophyid mite species, are not described yet, worldwide. Retracrus costaricensis, from Heliconia latispatha, was included by the correct identification, since 2012, was recorded as $R$. johnstoni. Symptoms description of some relevant species were included, supported by pictures of plant damage. Accordingly, the report of phytophagous mite species in Costa Rica, was updated from 2013 to 2018.

productoras, investigadoras, estudiantes, en el ámbito nacional como internacional. Estos registros fueron publicados en la Revista Agronomía Costarricense como apoyo al conocimiento de ácaros de importancia agrícola de Costa Rica (Aguilar y Murillo 2008, 2012). Estos artículos representan una continuación del trabajo de Freitez (1974), en su estudio de ácaros de la familia Tetranychidae, seguido por la revisión hecha por Salas (1978). Posteriormente, se publicó una guía de ácaros fitófagos para Centroamérica, donde se recopiló la información existente para la región, que incluye a Costa Rica, hasta 1991 (Ochoa et al. 1991, 1994). Estos registros pueden ser encontrados en la base de datos electrónica sobre la familia Tetranychidae creada por Migeon y Dorkeld (2018). Esta compilación de 
información referente a los daños provocados por ácaros fitófagos fue también aplicada por de Moraes y Flechtmann (2008) para Brasil, aunque estos autores incluyeron también otros ácaros que son de importancia en sistemas agrícolas, no solamente los causantes de daños a las plantas.

La combinación de los nuevos registros para Costa Rica, desde 2002 hasta 2012, ofrece 222 datos de ácaros fitófagos, agrupados en 81 familias de plantas, de los cuales algunos de ellos son de gran importancia como plagas de cultivos (Aguilar y Murillo 2008, 2012). Es importante reconocer que la familia Tetranychidae, ácaros conocidos como arañitas rojas o simplemente arañitas, dada su semejanza con diminutas arañas, es la que más representantes alcanza cada año. Algunas de sus especies como Tetranychus urticae Koch son altamente polífagas por lo que, año con año, aumenta el número de plantas hospedantes, cuyas familias han sido consignadas en todas las publicaciones mencionadas, además de la presente. Asimismo, otras especies pertenecientes a este género fueron registradas y asociadas con nuevas plantas hospedantes en Costa Rica. Igualmente, otros representantes de la mencionada familia, como son los géneros Eotetranychus, Eutetranychus, Mononychellus, Panonychus y, especialmente, Oligonychus, con un número significativo de especies, también fueron encontrados en nuevos hospederos.

El ámbito de acción de los ácaros tetraníquidos es sumamente extenso, se pueden incluir numerosas plantas ornamentales, tanto de flores como de follaje y árboles, además, de cultivos que se emplean como alimento y otros. Algunos productos son empleados en el mercado local, mientras que otros se utilizan como materiales para la exportación a diversos países, de ahí la importancia de conocer las especies que están asociadas a esas plantas hospedantes (Ochoa et al. 1991, 1994, Aguilar y Murillo 2008, 2012).

De la misma forma, los ácaros planos, que pertenecen a la familia Tenuipalpidae, son representantes permanentes de la acarofauna costarricense. Como parte de los objetivos de un proyecto relacionado con la búsqueda de especies de ácaros del género Brevipalpus asociadas a cítricos, principalmente las transmisoras del virus de la leprosis de los cítricos (CiLV), se hallaron especies que no habían sido localizadas antes en el país. Para esto, se realizó una búsqueda minuciosa en plantaciones de este cultivo, en concomitancia con algunos muestreos realizados en patios caseros del país.

La familia Tuckerellidae es monogenérica, ya que se conoce únicamente el género Tuckerella, compuesto por un poco más de 30 especies a nivel mundial (Beard y Walter 2005, Beard et al. 2013), de las que se han informado 6 para Costa Rica. Sólo T. knorri fue informada en una ocasión, por un severo daño causado en una plantación comercial de Citrus latifolia $(=C$. limon var. Mesina) (Aguilar et al. 1990). Hasta la fecha no se han reportado más daños de importancia económica en el país de este género de ácaros poco estudiados en aspectos como la biología, ecología o como plagas, tanto a nivel nacional como internacional. Existen sospechas de que algunos de ellos podrían tener un estatus de plaga, como es el caso de la especie T. japonica Ehara, de la que se intuye que podría tener un impacto en plantas de té, Camelia sinensis (L.) Kuntze (Beard et al. 2013). Sin embargo, todavía no se le ha dado esa condición, ya que se encuentra en estudio y aún los investigadores de esta familia de ácaros poseen muchas interrogantes relacionadas con el comportamiento de esta especie.

Polyphagotarsonemus latus (Banks) es un ácaro que siempre se ha visto con cautela extrema, dadas sus características de ácaro fitófago polífago, que puede ser encontrado en muchas plantas hospedantes, incluso en cultivos de notable importancia económica (Ochoa et al. 1991, 1994, Aguilar y Murillo 2008, 2012).

En Costa Rica, el ácaro blanco como es llamado, se conoce desde la década de 1970 y se halla por primera vez asociado con el cultivo de chile dulce (LA. Salas. 1983. Universidad de Costa Rica. Comunicación personal), ámbito de plantas hospedantes que ha crecido notablemente desde entonces. 
Los eriófidos, ácaros vermiformes de 4 patas en todos sus estadios, son siempre encontrados asociados con diversas plantas. Es una familia de ácaros con numerosas especies que, en su gran mayoría, aún no han sido descritas para la ciencia. Siempre que un ácaro eriófido es encontrado en el país, se consultan las publicaciones o catálogos internacionales y, por lo general, las especies recolectadas no se encuentran en la literatura, lo que confirma que aún no se han descrito entre un $95 \%$ y un $97 \%$ de las especies halladas en Costa Rica (Aguilar y Murillo 2012). Por lo tanto, al no tener una identificación fehaciente, se clasifican como expuestos si estos vagan por la superficie del sustrato o no expuestos, si están asociados con agallas, ampollas, erinosis u otra deformación de la planta que pueda servir de refugio para ellos. Asimismo, si la especie en cuestión está asociada con algún cultivo o planta de relevancia económica y se desconoce su clasificación, se le envía el material a algún especialista de este grupo, debido a las implicaciones que podría tener a futuro.

El objetivo de este trabajo es renovar el inventario de las especies de ácaros fitófagos en Costa Rica para el período 2013-2018. Asimismo, se ofrece información relacionada con reconocimiento, hábitos y biología de varias de las especies registradas y que podrían tener alguna relevancia de índole económica.

\section{MATERIALES Y MÉTODOS}

El Laboratorio de Acarología mantiene los métodos de procesamiento de material descritos por Aguilar y Murillo (2008). Una considerable parte del material procesado, entre 2013 y 2018, ha sido traída al laboratorio por personas interesadas en conocer la identidad de los ácaros que afectan sus cultivos, aunque también se solicitó el servicio de identificación de ácaros de materiales, que pueden ser considerados sui generis, i.e., asociados con animales silvestres, alimentos para animales domésticos o colecciones de materiales vegetales in vitro. Del mismo modo, parte del material registrado ha sido recolectado por personal del laboratorio en giras de muestreo a diferentes partes del país.

El material recogido fue montado en solución Hoyer (Krantz y Walter 2009), colocado en una estufa a $40^{\circ} \mathrm{C}$ por al menos 3 días, o bien, por el tiempo necesario hasta que los especímenes alcanzaran la clarificación adecuada. Posteriormente, las láminas fueron selladas con barniz, poliuretano brillante. Los especímenes fueron identificados con el uso de claves taxonómicas publicadas para cada familia, género y/o especie. Además, se contó con la ayuda de microscopios Olympus B 51 con contraste de fases y DIC, y Meiji MX 5310OH, también con contraste de fases.

Los ácaros de la familia Tetranychidae fueron identificados con el empleo de claves taxonómicas utilizadas en Aguilar y Murillo (2008): Pritchard y Baker (1955), Jeppson et al. (1975), Tuttle et al. (1976), Gutierrez (1985), además, de Baker y Tuttle (1994) y las descripciones incluidas en Ochoa et al. (1991 y 1994), y Seeman y Beard (2011).

Con respecto a los ácaros de la familia Tenuipalpidae, se emplearon las claves de Pritchard y Baker (1958), Ochoa y Salas (1989), Mesa et al. (2009) y Beard et al. (2012, 2015) y las descripciones encontradas en Ochoa et al. (1991 y 1994). Por su parte, las especies de la familia Tuckerellidae, cuyo único género es Tuckerella, se identificaron con la clave que Ochoa (1989) publicó para las especies de Costa Rica en conjunto con las publicaciones de Ochoa et al. (1991 y 1994); asimismo, se empleó la clave publicada por Meyer y Ueckermann (1997).

En lo que respecta a los ácaros tarsonémidos, se utilizaron las claves de Lindquist (1986), Ochoa et al. (1991) y descripciones anotadas en Ochoa et al. (1991 y 1994).

Para identificar a los ácaros de la familia Eriophyidae, se empleó las claves de Jeppson et al. (1975), Keifer et al. (1982), Amrine y Stasny (1994), además, de las descripciones encontradas en Ochoa et al. 1991 y 1994. Asimismo, se emplearon las técnicas de montaje sugeridas por De Lillo et al. (2010) para este tipo de ácaros. 
Finalmente, cuando hubo necesidad de consultar con expertos en los diversos grupos de ácaros, el material fue enviado al especialista para verificar las identificaciones llevadas a cabo en el Laboratorio de Acarología o, en su defecto, para una identificación precisa del espécimen. El material montado se encuentra depositado en la colección de Ácaros de Importancia Agrícola del Laboratorio de Acarología.

Se llevó un registro fotográfico de la sintomatología mostrada por las diferentes plantas hospedantes, tanto en campo como en laboratorio, utilizando una cámara digital Canon EOS Rebel XSi.

\section{RESULTADOS Y DISCUSIÓN}

En esta entrega 75 nuevos registros son incluidos, los que están asociados con las 6 familias más reconocidas de ácaros fitófagos:
Tetranychidae, Tenuipalpidae, Tuckerellidae, Tarsonemidae, Eriophyidae y Phytoptidae, relacionadas con 30 familias de plantas hospedantes.

Estos nuevos hallazgos se pueden apreciar en las Tablas del 1 al 5, donde fueron agrupados por especie del ácaro, planta hospedante y familia de la planta. Como se puede observar, los ácaros pertenecientes a la familia Tetranychidae (Tabla 1) son los más numerosos. Cada año, aparecen nuevas asociaciones ácaroplanta que se consignan en la base de datos perteneciente al área de Acarología, donde los registros se hacen en el momento en que se recibe la muestra. Además, de presentar poblaciones más altas que otros ácaros, son muy evidentes por la sintomatología que muestran las plantas hospedantes; por lo general, esta es conspicua y, en la mayoría de los casos, está acompañada con la tela producida por el ácaro, que puede ser profusa o escasa. 
Tabla 1. Ácaros de la familia Tetranychidae encontrados e identificados para Costa Rica en el periodo 2013-2018 con sus respectivas plantas hospederas.

\begin{tabular}{|c|c|c|}
\hline Especie de ácaro & Hospedero & Familia \\
\hline Eotetranychus deleoni & Phaseolus coccineus L. (cubá) & Fabaceae \\
\hline Eotetranychus sp. & Bactris gasipaes Kunth (pejibaye) & Palmae \\
\hline Eutetranychus sp. & Solanum melongena L. (berenjena) & Solanaceae \\
\hline Mononychellus sp. (Sólo hembras) & Diphysa americana (Mill.) M. Sousa (guachipelín) & Fabaceae \\
\hline Oligonychus gossypii & Bauhinia variegata L. (orquídea de palo) & Fabaceae \\
\hline Oligonychus mcgregori & Inga jinicuil G. Don & Fabaceae \\
\hline \multirow[t]{4}{*}{ Oligonychus punicae } & Alocasia plumbea Van Houtte & Araceae \\
\hline & Pinanga kuhlii Blume (pinanga) & Arecaceae \\
\hline & Tectona grandis L.f (Teca) & Lamiaceae \\
\hline & Trichilia havanensis Jacq. (uruca) & Meliaceae \\
\hline \multirow[t]{2}{*}{ Oligonychus yothersi } & Acacia melanoxylon $\mathrm{R} . \mathrm{Br}$ (acacia) & Fabaceae \\
\hline & $\begin{array}{l}\text { Chamaedorea costaricana Oerst (pacaya) } \\
\text { Syngonium podophyllum Schott }\end{array}$ & $\begin{array}{l}\text { Arecaceae } \\
\text { Araceae }\end{array}$ \\
\hline Oligonychus zeae & Elaeis guineensis L. (Palma aceitera) & Arecaceae \\
\hline Oligonychus sp. (Sólo hembras) & $\begin{array}{l}\text { Bactris gasipaes Kunth (pejibaye) } \\
\text { Celaenodendron mexicanum Standl. }\end{array}$ & $\begin{array}{l}\text { Arecaceae } \\
\text { Picrodendraceae }\end{array}$ \\
\hline \multirow[t]{2}{*}{ Panonychus citri } & Citrus reticulata Blanco (mandarina) & Rutaceae \\
\hline & Rosa L. sp. (rosa) & Rosaceae \\
\hline Schizotetranychus sp. & Fargesia robusta T. P Yi (bambú) & Poaceae \\
\hline \multirow[t]{2}{*}{ Tetranychus cinnabarinus } & Bactris gasipaes Kunth (pejibaye) & Arecaceae \\
\hline & Solanum melongena L. (berenjena) & Solanaceae \\
\hline Tetranychus mexicanus & Elaeis guineensis L. (Palma aceitera) (en invernadero) & Arecaceae \\
\hline Tetranychus neocaledonicus & $\begin{array}{l}\text { Polyscias balfouriana (André) L.H. Bailey } \\
\text { Myrtus communis L. (Mirto) }\end{array}$ & $\begin{array}{l}\text { Araliaceae } \\
\text { Myrtaceae }\end{array}$ \\
\hline Tetranychus turkestani & Passiflora ligularis Juss. (granadilla) & Passifloraceae \\
\hline \multirow[t]{10}{*}{ Tetranychus urticae } & Agastache J. Clayton ex Gronov. sp. & Lamiaceae \\
\hline & Aglaonema commutatum Schott & Araceae \\
\hline & Amsonia Walter sp. & Apocynaceae \\
\hline & Arracacia xanthorrhiza Bancr. (Arracache) & Apiaceae \\
\hline & Buddleia L. sp. & Scrophulariaceae \\
\hline & Brunfelsia pauciflora (Cham. \& Schltdl.) Benth (San Juan) & Solanaceae \\
\hline & Cucumis melo L. (melón) & Cucurbitaceae \\
\hline & Chamaedorea cataractarum Mart. & Arecaceae \\
\hline & $\begin{array}{l}\text { Chamaedorea costaricana Oerst. (pacaya) } \\
\text { Datura metel L. (trompeta del diablo) }\end{array}$ & $\begin{array}{l}\text { Arecaceae } \\
\text { Solanaceae }\end{array}$ \\
\hline & Fatsia japonica (Thunb.) Decne. \& Planch (aralia) & Araliaceae \\
\hline
\end{tabular}




\begin{tabular}{lll}
\hline Especie de ácaro & Hospedero & Familia \\
\hline & Fragaria L. sp. cv. Albion (fresa) & Rosaceae \\
& Galinsoga parviflora Cav. & Asteraceae \\
& Monarda L. sp. & Lamiaceae \\
& Mucuna pruriens Scop. (mucuna) & Fabaceae \\
& Musa velutina H. Wendl. \& Drude (banano ornamental) & Musaceae \\
& Myrrhis odorata (L.) Scop. (Mirra) & Apiaceae \\
& Ocimum basilicum L. (albahaca) & Lamiaceae \\
& Passiflora edulis Sims (maracuyá) & Passifloraceae \\
& Passiflora ligularis Juss. (granadilla) & Passifloraceae \\
& Phaseolus L. sp. & Fabaceae \\
& Phaseolus coccineus L. (cubá) & Fabaceae \\
& Phlox L. sp. & Polemoniaceae \\
& Solanum ovigerum Dunal (planta del huevo) & Solanaceae
\end{tabular}

Tabla 2. Ácaros de la familia Tarsonemidae encontrados e identificados para Costa Rica en el período 2013-2018 con sus plantas hospederas.

\begin{tabular}{lll}
\hline Especie de ácaro & Hospedero & Familia \\
\hline Polyphagotarsonemus latus & Citrus volkameriana Ten. \& Pasq. (patrón) & Rutaceae \\
& Malus domestica Borkh. cv. Ana (manzana) & Rosaceae \\
& Physalis peruviana L.(uchuva) & Solanaceae \\
& Vigna radiata (L.) R. Wilczek (Vigna) & Fabaceae \\
Phytonemus pallidus & Fragaria L. sp. cv. Albion (fresa) & Rosaceae \\
Steneotarsonemus $\mathrm{sp}$. & Neoregelia L.B. Sm. sp. & Bromeliaceae \\
\hline
\end{tabular}


Tabla 3. Ácaros de la familia Tenuipalpidae encontrados e identificados para Costa Rica en el período 2013-2018 con sus plantas hospederas.

\begin{tabular}{lll}
\hline Especie de ácaro & Hospedero & Familia \\
\hline Brevipalpus azores & Syngonium Schott sp. & Araceae \\
Brevipalpus californicus especies grupo B & Syngonium Schott sp. & Araceae \\
Brevipalpus papayensis & Elaeis guineensis Jacq. (Palma aceitera) & Arecaceae \\
Brevipalpus phoenicis & Elaeis guineensis Jacq. (Palma aceitera) & Arecaceae \\
Brevipalpus yothersi & Asparagus L. sp. (espárrago ornamental) & Asparagaceae \\
Brevipalpus sp. & Brunfelsia pauciflora (Cham. \& Schltdl.) Benth (San Juan) & Solanaceae \\
& Cuphea gracilis Kunt & Lythraceae \\
& Grammatophyllum scriptum (L.) Blume & Orchidaceae \\
& Ligustrum L. sp. & Oleaceae \\
& Sapium Jacq. sp. & Euphorbiaceae \\
\hline
\end{tabular}

Tabla 4. Ácaros de la familia Tuckerellidae encontrados e identificados para Costa Rica en el período 2013-2018 con sus respectivas plantas hospederas.

\begin{tabular}{lll}
\hline Especie de ácaro & Hospedero & Familia \\
\hline Tuckerella ornata & Schefflera arboricola variegata (Hayata) Merr. & Araliaceae \\
Tuckerella sp. & Ligustrum L. sp. & Oleaceae \\
\hline
\end{tabular}

Tabla 5. Ácaros de la superfamilia Eriophyioidea encontrados e identificados para Costa Rica en el período 2013-2018 con sus plantas hospederas.

\begin{tabular}{lll}
\hline Especie de ácaro & Hospedero & Familia \\
\hline Familia Eriophyidae & & Poaceae \\
Eriophyidae (expuesto) & Fargesia robusta T. P Yi (bambú) & Phyllanthaceae \\
Eriophyidae (expuesto) & Hieronyma alchorneoides Allemão & Oleaceae \\
Eriophyidae (expuesto) & Ligustrum L. sp. & Euphorbiaceae \\
Eriophyidae (expuesto) & Sapium Jacq. sp. & Fabaceae \\
Eriophyidae (no expuesto) & Sclerolobium costaricense N. Zamora \& Poveda & Heliconiaceae \\
Familia Phytoptidae & & Heliconia latispatha Benth. (heliconia) \\
Retracrus costaricensis & &
\end{tabular}

Es importante recalcar que, con respecto a los registros de Brevipalpus, ácaro plano perteneciente a la familia Tenuipalpidae, se hizo una actualización de los datos con base en la revisión exhaustiva del género que hicieron
Beard et al. (2012). Así, de esa forma, ya queda dicho reajuste para Costa Rica. En este caso en particular, no sólo se encontraron nuevas especies de plantas hospedantes, sino también especies de Brevipalpus que no habían sido 
informadas antes para Costa Rica o, incluso, para ningún país de la región.

La composición de las 6 familias de ácaros fitófagos, que fueron registradas para el período mencionado, están expresadas en la Figura 1, donde Tetranychidae ocupa un $70,7 \%$ del total de nuevos registros; Tenuipalpidae, con diversas especies de Brevipalpus ocuparon un 10,6\%, mientras que Tarsonemidae aportó un $8,0 \%$ del total. Por su parte, Tuckerellidae, con 2 plantas hospedantes, obtuvo un 2,7\% del valor total. Por último, Eriophyidae y Phytoptidae representaron un $6,7 \%$ y $1,3 \%$ del total de registros, respectivamente.

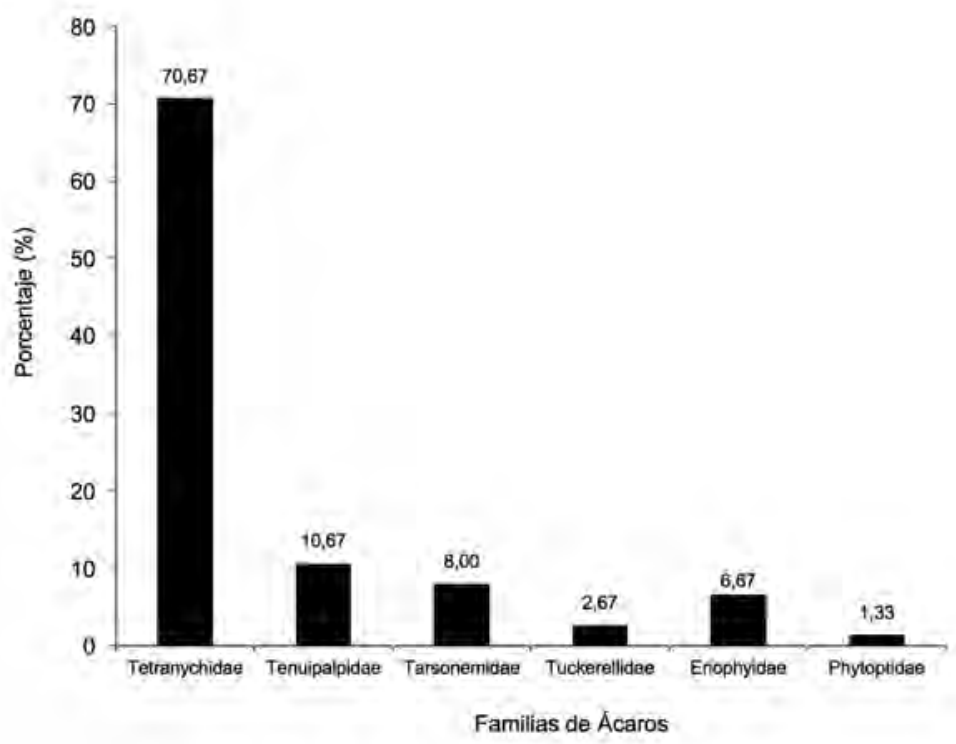

Figura 1 Porcentaje de familias de ácaros fitófagos hallados en Costa Rica entre 2013-2018.

En este período, no hubo recolección de nuevos hospedantes para la familia Phytoptidae, que son encontrados con frecuencia en algunas palmas y en los últimos años en heliconias también, que Aguilar y Murillo (2012) consignaron como Retracrus johnstoni Keifer, asociado con la especie Heliconia latispatha (Benth.). Sin embargo, luego de un exhaustivo estudio realizado con taxonomía tradicional y morfometría por Navia et al. (2015), esos autores encontraron que se trataba de una nueva especie, a la que describieron como $R$. costaricensis. La confusión se mantuvo por muchos años, debido a su alta semejanza con la especie $R$. johnstoni, la cual se encuentra con frecuencia en Costa Rica asociada con Chamaedorea costaricana Oerst., una palma ornamental conocida como pacaya. Aguilar y Murillo (2012) hacen una detallada descripción del daño provocado por esa especie en H. latispatha; sin embargo, el síntoma difiere notablemente del provocado en la pacaya. Se incluye en la Tabla 5 la especie correcta luego del estudio mencionado.

\section{RECONOCIMIENTO DE CAMPO}

\section{Familia Tetranychidae}

Los ácaros de esta familia, conocidos como arañitas rojas, son nuevamente los que se encuentran en mayor abundancia asociados con nuevas plantas hospedantes para el país (Aguilar y Murillo 
2008, 2012) y, quizá, muchos de estos hospederos no han sido informados hasta la fecha como hospedantes de tetraníquidos en otros países del mundo (Migeon y Dorkeld 2018). Una vez más, el ácaro de 2 manchas, T. urticae, se constituye como la especie con el mayor número de plantas hospedantes para el período en que se registraron estos datos.

Como se ha hecho en los artículos que preceden a esta entrega, se elaborará una descripción de síntomas en algunas plantas hospedantes, basados en la observación de los daños presentes en las mismas; algunas de ellas de considerable importancia económica. Por lo tanto, es información generada en la Clínica de Diagnóstico de Ácaros y, al ser descripciones originales, no se encuentra en la literatura vigente.

\section{Eotetranychus sp. en Acnistus arborescens Schlecht (Solanaceae)}

Las hojas muestran una clorosis generalizada por el haz (Figura 2A). Los ácaros se observan tanto en el haz como en el envés. Aquí se concentran las mayores densidades de este ácaro, que es pequeño y levemente alargado, a diferencia de otros tetraníquidos, que son globosos. Son de una tonalidad que va de un color blanco-amarillento a verdoso y se observan muy activos. Se aprecia una gran cantidad de mudas y los ácaros emplean la tela para movilizarse de un lugar a otro en el sustrato; algunos se notan alimentándose con avidez en el mismo.
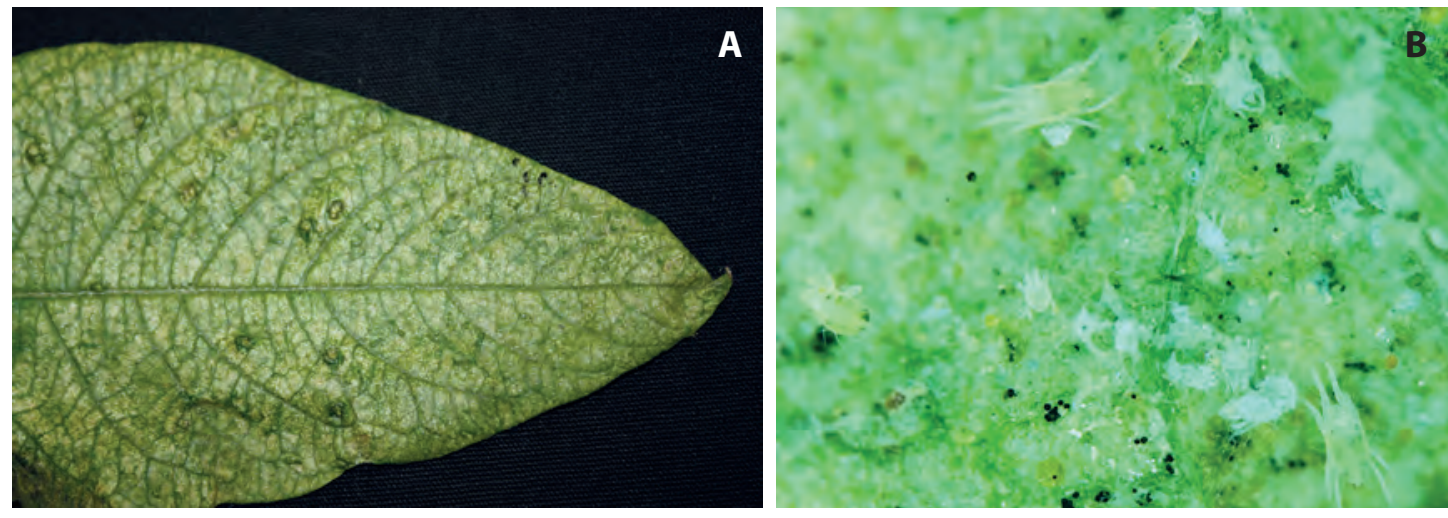

Figura 2 A) Clorosis provocada por Eotetranychus sp. en hoja de güitite. B) Formas móviles del ácaro Eotetranychus sp. en el follaje de güitite.

La coloración clara de los ácaros contrasta con algunas manchas oscuras observadas a lo largo del idiosoma. Las manchas oculares de todos los estadios son muy marcadas (Figura 2B). Los huevos son esféricos y transparentes, no se observa presencia de estipe dorsal. Estos son depositados principalmente sobre la tela. Algunos de los estadios inmaduros se aprecian de color verde, muy probablemente por haberse alimentado recientemente.
Las agallas del güitite, que son inducidas por otro ácaro, Eriophyes sp. de la familia Eriophyidae, no son esféricas o alargadas como ocurre con las provocadas por otros artrópodos (Keifer et al. 1982), sino que presentan un achatamiento dorso ventral con algunas pequeñas cavidades, las que son empleadas por las hembras del tetraníquido para ovipositar así como para refugio (Figura 2A).

De igual forma, es común observar a los ácaros a lo largo de la vena media, donde se 
distinguen numerosas mudas adheridas al sustrato. Allí también se perciben muchos individuos llamados crisálidas, que son estados quiescentes que ocurren entre una muda y otra, tal como ácaros móviles y muy activos.

\section{Oligonychus gossypii (Zacher) en orquídea de palo (Bauhinia variegata $\mathrm{L}$.)}

Este ácaro fue mencionado por Ochoa et al. (1991, 1994), asociado con orquídea de palo, pero no se había incluido la especie de Bauhinia en donde se había localizado. Ahora, se corrobora que se trata de $B$. variegata, un árbol ornamental que se emplea con frecuencia para adornar jardines y áreas verdes, debido a su exuberancia.

Las poblaciones del ácaro se encuentran en el haz de las hojas, las que generalmente empiezan desde la región proximal de la hoja y se extienden hasta la distal (Figura 3). Según sea la densidad de los ácaros, se puede apreciar una clorosis de las láminas que podría ser de grandes proporciones. La cantidad de tela producida por $O$. gossypii no parece ser muy grande en comparación con la producida por otras especies de tetraníquidos. Ochoa et al. $(1991,1994)$ mencionan que esta especie ataca al higuerón (Ficus sp.) e indican que los individuos se localizan en el envés de las hojas, comportamiento totalmente disímil al observado en orquídea de palo.

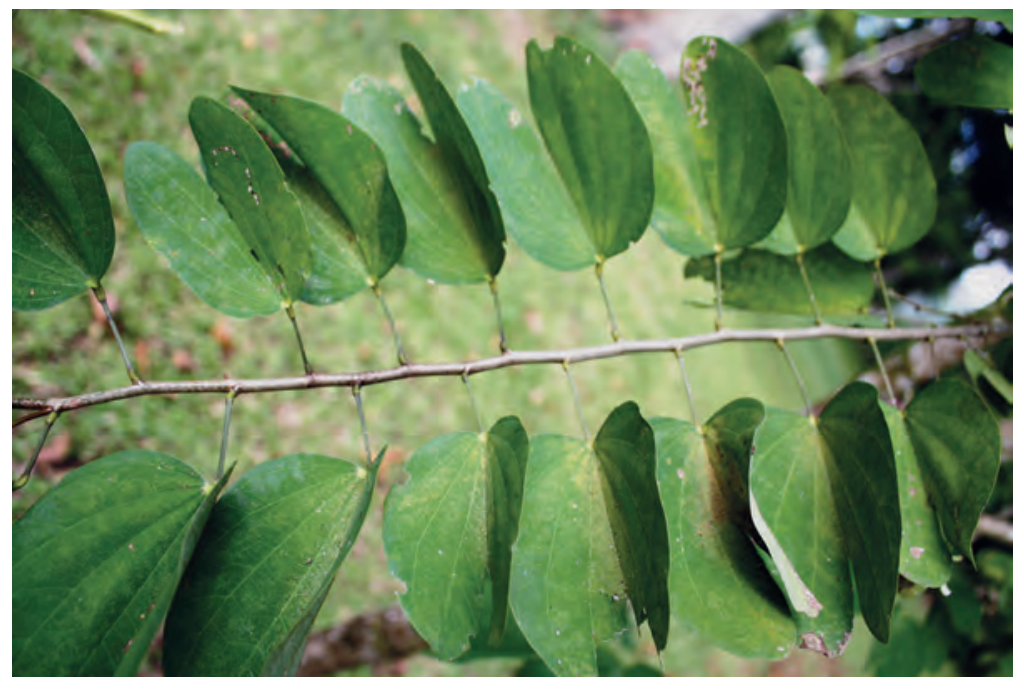

Figura 3 Daño provocado por Oligonychus gossypii en el follaje de Bauhinia variegata.

\section{Oligonychus punicae (Hirst) en alocasia (Alocasia plumbea Van Houtte), pinanga (Pinanga kuhlii Blume) y uruca (Trichilia havanensis Jacq.)}

Como es característico en gran cantidad de especies del género Oligonychus, las colonias de este ácaro se localizan en el haz de las hojas (Ochoa et al. 1991, 1994). En principio, las poblaciones se ubican a los lados de las venas, tanto la principal como las secundarias en el follaje de alocasia. Luego, debido al crecimiento en número de los ácaros, la colonización se extiende por toda la lámina. Los ácaros son fácilmente localizables, ya que producen abundante tela y una gran cantidad de mudas quedan adheridas a la lámina, lo que coincide con la densidad de la población (Figura 4). Las hojas 
presentan una clorosis tenue que luego de albergar grandes poblaciones por un tiempo, tornan la decoloración más notable, especialmente marcada en la vena media y hacia el ápice de la lámina.

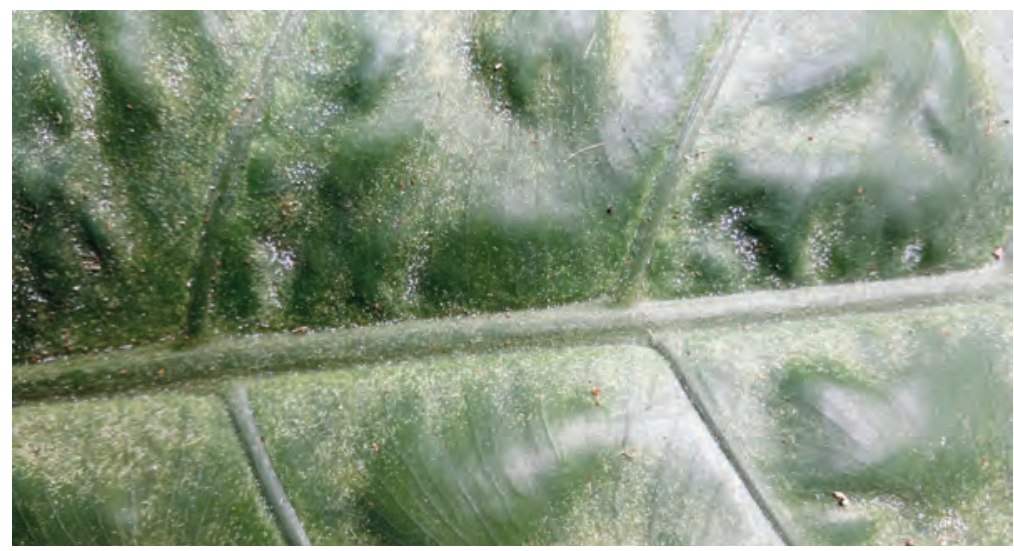

Figura 4 Haz de una hoja de Alocasia plumbea, observándose la tela y mudas depositadas por Oligonychus punicae.

Estas son plantas ornamentales de follaje que debido a su belleza, se emplean con frecuencia en jardines. Cuando ocurre un ataque por parte de $O$. punicae, se pierde la tonalidad verde característica de las plantas y así, se observan estas con una coloración medianamente plateada.

En P. kuhlii, los ácaros también se localizan en el haz de los foliolos, lo que provoca un bronceado principalmente a los lados de las venas. Es común observar cuando las densidades poblacionales son muy altas, las formas móviles de los ácaros y los huevos en esas áreas con abundante presencia de detritos que se adhieren a la tela producida por el ácaro (Figuras 5A y 5B). Los daños se presentan en las frondas más desarrolladas y al observar la planta como un todo, se aprecia un considerable contraste en la coloración del follaje. Esta palma que fue introducida de Indonesia en el sureste asiático, también se emplea como ornamental. Está localizada, especialmente, en áreas cálidas del país, como en la ciudad de Turrialba en la provincia de Cartago, que fue donde se recolectó el material en estudio.
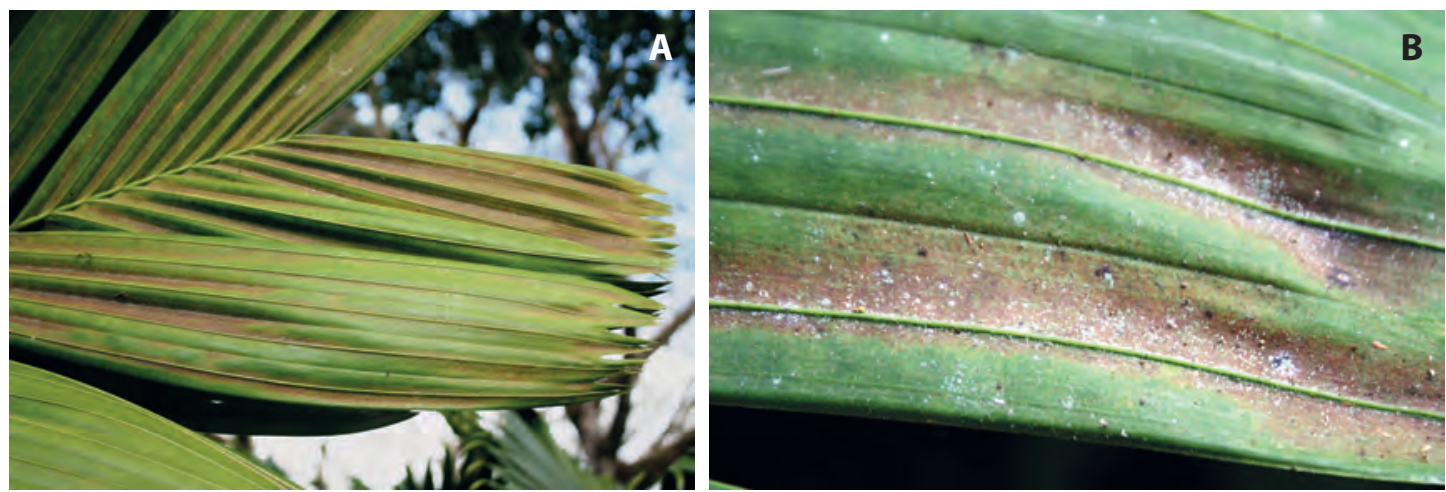

Figura 5 A) Síntoma producido por Oligonychus punicae en fronda de Pinanga kuhlii. B) Detalle de hoja de pinanga, afectada por la alimentación del ácaro. 
En Uruca, el síntoma producido por el ataque de esta especie se puede describir como una clorosis intervenal que asemeja a una deficiencia de magnesio (Figura 6). Los ácaros se localizan a ambos lados de las venas de las hojas, especialmente de la principal. Allí se pueden observar todos los estadios del ácaro, por lo general cubiertos con una no muy abundante tela. Es común que partículas de polvo y otros detritos queden adheridos a esas telas, así como los huevos que presentan, como característica particular, estipe dorsal. También es común observar exuvias adheridas a la superficie del sustrato, a todo lo largo del daño.

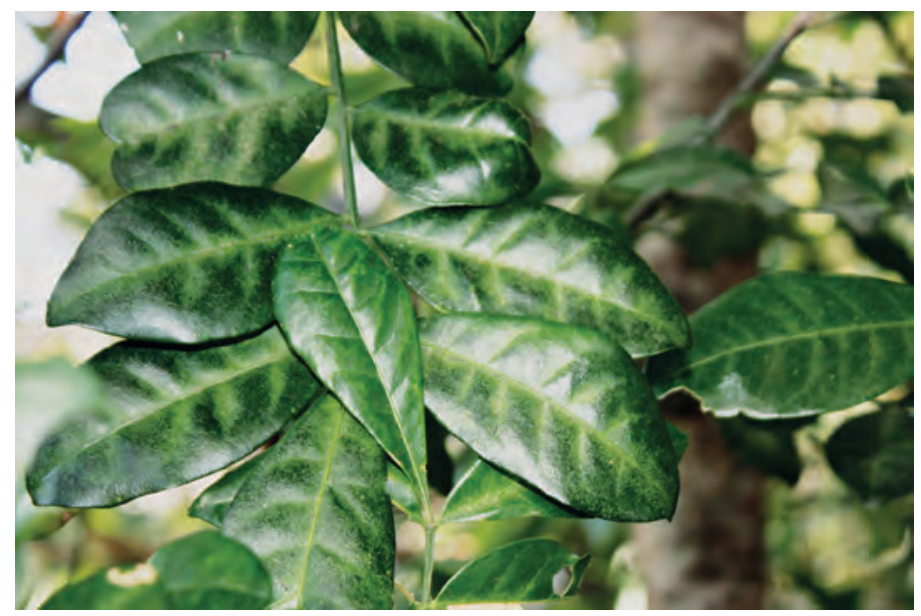

Figura 6 Síntoma provocado por Oligonychus punicae en Trichilia havanensis.

\section{Oligonychus yothersi (McGregor) en Syngonium podophyllum Schott (Araceae)}

Al igual que sucede con otras especies del género Oligonychus, los individuos asociados con esta planta se localizan en el haz de las hojas, especialmente a lo largo de la vena media. Forman una tela que prácticamente cubre la vena longitudinalmente y es un sitio empleado para ovipositar, así como para mudar, por lo que es posible apreciar aun sin la ayuda de una lupa, una gran cantidad de exuvias agrupadas allí, así como en formas móviles (Figuras 7A y 7B). De igual forma emplean las venas secundarias de la hoja para depositar sus mudas, por lo que se observa un patrón similar al descrito para la vena central.
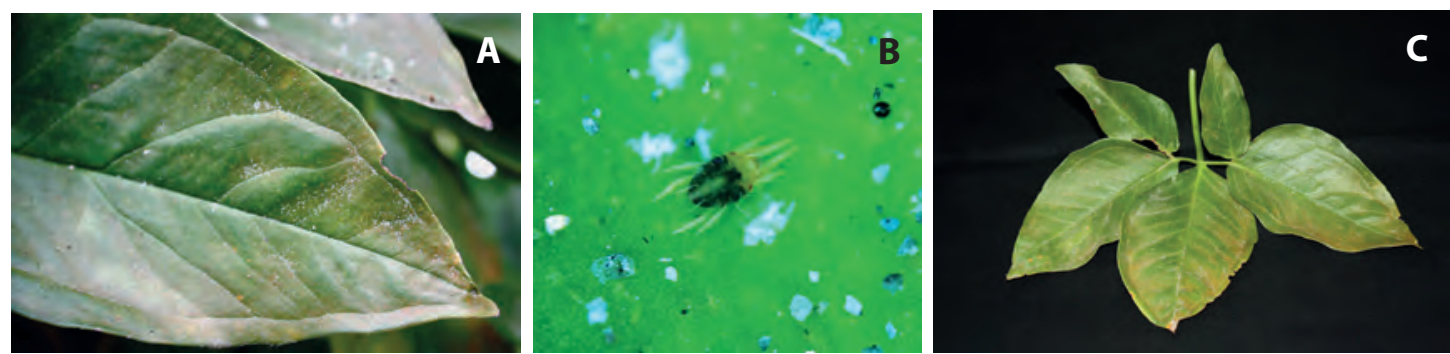

Figura 7 A) Síntoma producido por Oligonychus yothersi en Syngonium podophyllum, observándose una numerosa cantidad de exuvias. B) Hembra de O. yothersi sobre una hoja de Syngonium podophyllum. C) Bronceado producido por O. yothersi en follaje de Syngonium podophyllum. 
Los ácaros al cubrir la vena central con su tela, forman una especie de refugio que les sirve para protegerse del clima, así como de posibles depredadores (Gerson 1985); además, les permite su libre movilización del ápice a la base de la hoja y viceversa. La tela favorece la acumulación de detritos en el follaje, por lo que estas no lucen pulcras al observarlas al ojo desnudo.

Las hojas se aprecian con un bronceado en el haz, que puede extenderse por toda la lámina, según sean las densidades poblacionales del ácaro (Figura 7C). Cuando estas son elevadas, la extensión del bronceado se aprecia más uniforme; si son poblaciones bajas, el síntoma se concentra donde se hallan los ácaros.

\section{Tetranychus neocaledonicus André en Myrtus communis L. (Myrtaceae)}

Las hojas muestran punteaduras cloróticas en el haz, las cuales coalescen para así formar una clorosis generalizada en el follaje (Figura 8A). Los ácaros se encuentran distribuidos por todo el envés de las hojas. Allí se puede apreciar una distribución uniforme de los ácaros y sus telas, acompañados con una gran cantidad de mudas. No se aprecia una preferencia por sitios para oviposición y muda en el sustrato, como sucede con otras especies de tetraníquidos. Sin embargo, es posible observar una acumulación de mudas en la base del pecíolo de las hojas. Igualmente, se distingue una decoloración casi absoluta en el envés de las hojas, con pequeñas manchas verdes en algunas áreas. Si las densidades del ácaro son muy elevadas, el envés de las hojas se aprecia completamente decolorado.
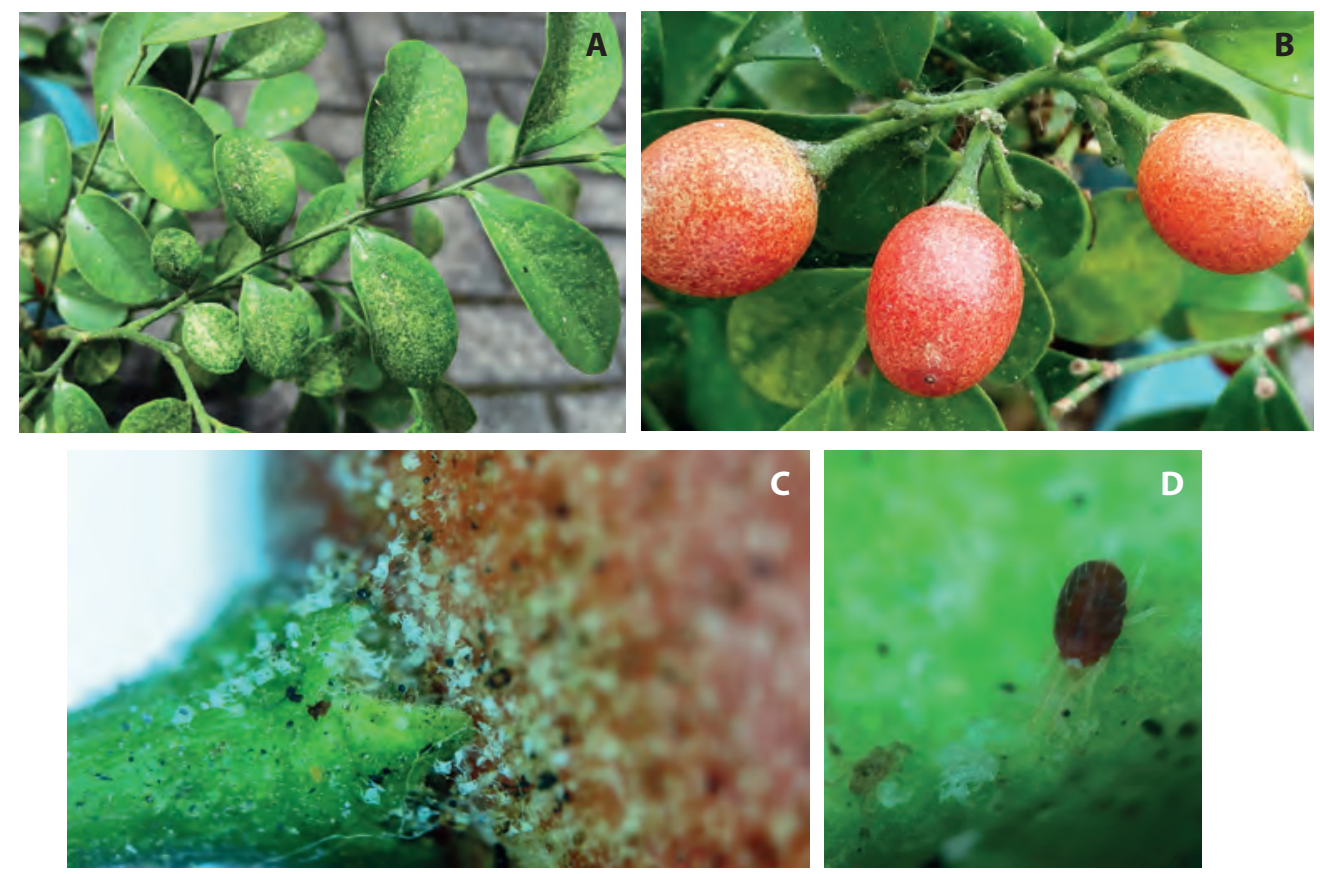

Figura 8 A) Clorosis en follaje de Myrtus communis provocada por Tetranychus neocaledonicus. B) Frutos de M. communis, atacados por T. neocaledonicus, C) Acercamiento del receptáculo de M. communis, con detalle de telas y mudas, D) Hembra de T. neocaledonicus en M. communis. 
El fruto también es atacado por esta especie y, debido a la alimentación, se distingue una decoloración del mismo que, al observarse con mayor detalle, es constituida por manchas blanquecinas por toda la superficie (Figura 8B). El receptáculo del fruto muestra una tela profusa, en donde se puede apreciar una considerable cantidad de mudas, lo que indica que es un sitio adecuado y escogido por el ácaro para llevar a cabo su metamorfosis. También es posible apreciar un número considerable de huevos y formas móviles (Figura 8C).

Las hembras del ácaro son de un color rojo intenso, con patas blancas o amarillentas, fáciles de ver aun con una lupa de baja magnificación, por el contraste que se produce con el sustrato (Figura 8D). Las ninfas, por su parte, tienden a ser de color anaranjado, las que se tornan rojas conforme maduran. Los huevos son esféricos y blanquecinos, que se tornan amarillentos cuando maduran y están próximos a eclosionar.

\section{Tetranychus urticae Koch en aralia (Fatsia japonica (Thunb.) Decne. \& Planch.)}

Hace varios años numerosos productores de helecho hoja de cuero (Rhumora adiantiformis [G. Forst.] Ching), de Costa Rica, cambiaron este cultivo por otro que presentaba grandes expectativas de mercado, como es la aralia $(F$. japonica). El cultivo de helecho hoja de cuero dejó de ser atractivo para los productores por, entre otras razones, problemas fitosanitarios de considerable importancia como la antracnosis, producida por el hongo Colletotrichum acutatum J.H. Simmonds (G. Umaña. 2018. Laboratorio de Poscosecha, CIA. Comunicación personal) y por el ataque del ácaro tarsonémido Hemitarsonemus tepidariorum Warburton (Aguilar y Murillo 2008). Asimismo, se consideraba que el mercado que recibiría el material de aralia era altamente promisorio.

Se ha encontrado que este cultivo puede ser severamente dañado por el ataque de varias especies de ácaros, i.e. Brevipalpus obovatus Donnadieu, Phytonemus pallidus (Banks), P. latus (Aguilar y Murillo 2008) y T. urticae, cuya sintomatología se describe en esta entrega.

Como es característico del ácaro T. urticae, sus colonias se encuentran en el envés de las hojas, principalmente aquellas que muestran un mayor grado de madurez. Las colonias se localizan desde la base de las hojas hasta el ápice, se reconoce por una decoloración de la superficie, además, de la tela que es característica de los ácaros tetraníquidos. Estas colonias ubicadas en el envés de las hojas coinciden con una clorosis intervenal por el haz (Figuras 9A y 9B), la cual es de un color amarillo intenso que contrasta grandemente con el color verde de las hojas. Si la infestación es intensa, se puede observar una generalización en la plantación y las plantas lucen como si tuvieran un follaje variegado. Los síntomas producidos por T. urticae difieren notablemente de aquellos producidos por B. obovatus en este cultivo (Figuras 9C y 9D), por lo que ambos se consideran de gran impacto y de considerable daño económico. Como se indicó previamente, los ácaros tarsonémidos ya aludidos, que atacan los brotes de las plantas, producen deformaciones de las partes más jóvenes. Así la sintomatología es marcadamente diferente entre las diversas especies que se asocian con $F$. japonica. 

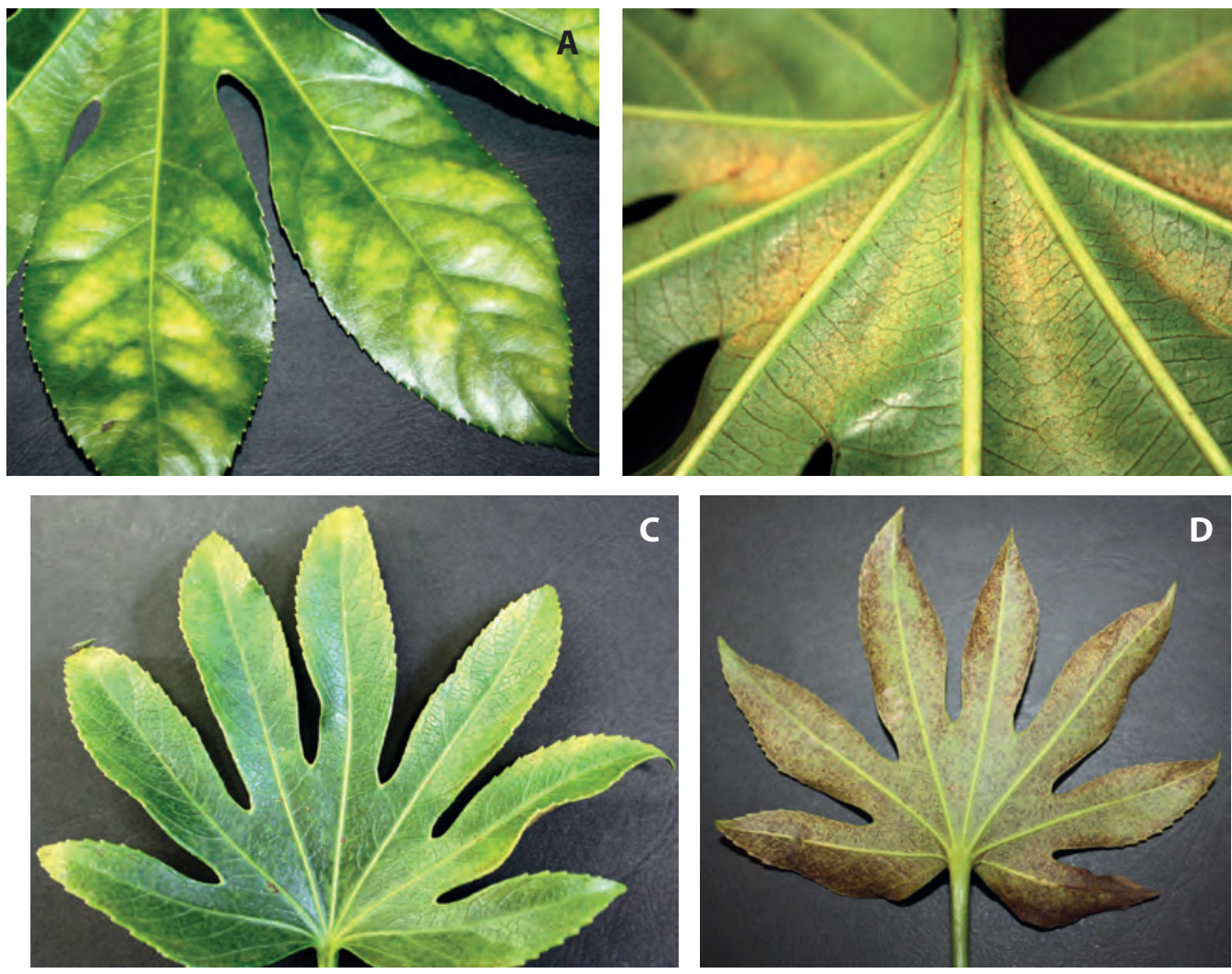

Figura 9 A) Haz del follaje de Fatsia japonica, mostrando clorosis producida por Tetranychus urticae, B) Envés del follaje de $F$. japonica mostrando áreas donde se ubican los ácaros, C) Síntoma producido por Brevipalpus obovatus en $F$. japonica (haz), D) Síntoma provocado por B. obovatus en F. japonica (envés).

\section{Otros daños provocados por tetraníquidos}

En Phaseolus coccineus L., el daño provocado por T. urticae es muy similar al producido en otras plantas hospedantes por esta misma arañita; se puede apreciar una clorosis en el haz de las hojas, producto de la coalescencia de las punteaduras formadas en los diversos sitios de alimentación. Así cuando las densidades de la arañita son altas, estas se encuentran por el envés de toda la lámina en cada uno de los foliolos (Figuras 10A y 10B). Es común localizar al principio a los ácaros a los lados de las venas, sin embargo, dada la competencia intraespecífica existente, estos se distribuyen a lo largo y ancho de la superficie foliar hasta que migran a otras hojas o bien, a otras plantas. Si no se efectúan medidas de combate a tiempo, las hojas llegan a necrosarse y se vuelven de una consistencia frágil, como de papel y, al final, se produce defoliación y muerte de la planta. 

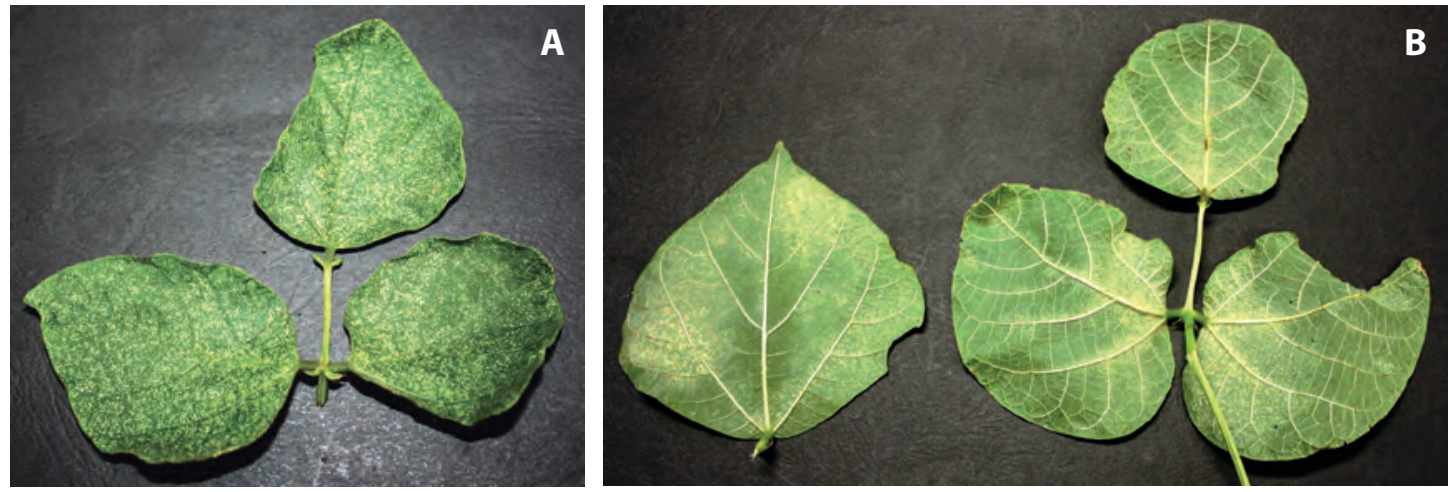

Figura 10 A) Síntoma producido por Tetranychus urticae en el haz del follaje de Phaseolus coccineus, B) Poblaciones de T. urticae en el envés de la hoja trifoliada de P. coccineus.

En Datura metel L., conocida como trompeta del diablo, se encontró una alta población de la forma roja de T. urticae, que compartía el follaje de la planta con una considerable población de áfidos (especie no identificada). Los síntomas producidos por la acción del ácaro se aprecian como parches cloróticos en diversas áreas de la hoja, lo cual se observa en el haz, lo que coincide con pequeños grupos de ácaros

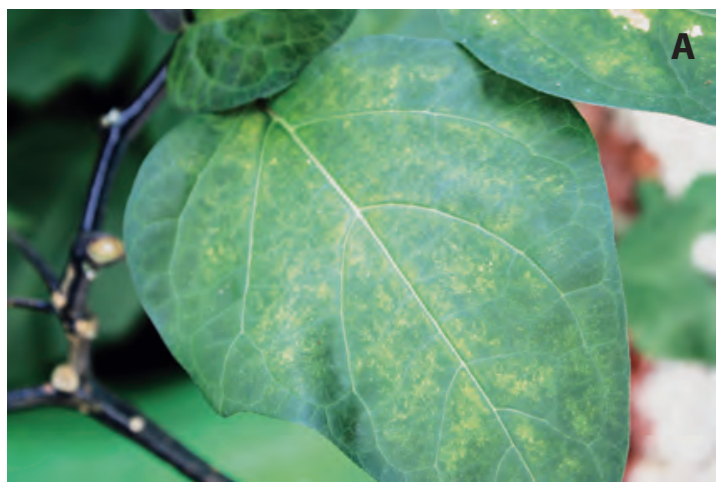

dispersos por el envés (Figura 11A). Como se aprecia en la Figura 11B, las poblaciones de cada artrópodo ocupaban sólo una parte de la lámina evitando así, la competencia interespecífica aunque en ocasiones la especie más grande, el áfido, podía invadir el área donde se encontraba la arañita roja, desplazándola hacia otros sitios de la hoja, o bien, otras hojas o plantas cercanas.

Figura 11 A) Clorosis provocada por Tetranychus urticae en Datura metel: superficie adaxial, B) Poblaciones de T. urticae y áfido no identificado en el envés de hoja de D. metel.

Se encontraron, también, poblaciones de T. urticae asociadas con banano ornamental, Musa velutina $\mathrm{H}$. Wendl. \& Drude en el

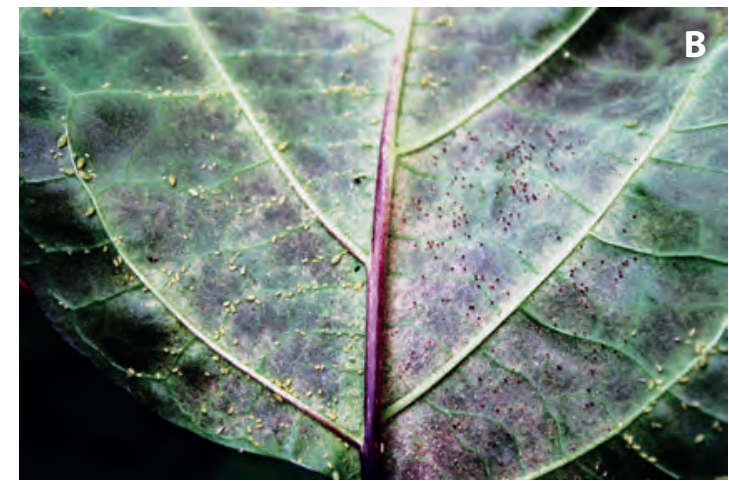

envés del follaje, que expone un bronceado a lo largo de las venas secundarias, y de manera perpendicular, a la vena principal (Figura 12). 
Este síntoma es muy similar al observado en banano comercial (Musa acuminata Colla) y que es producido por una especie cercana,
T. abacae Baker \& Pritchard, cuando no está muy extendido y el daño se aprecia poco severo (Ochoa et al. 1991, 1994).

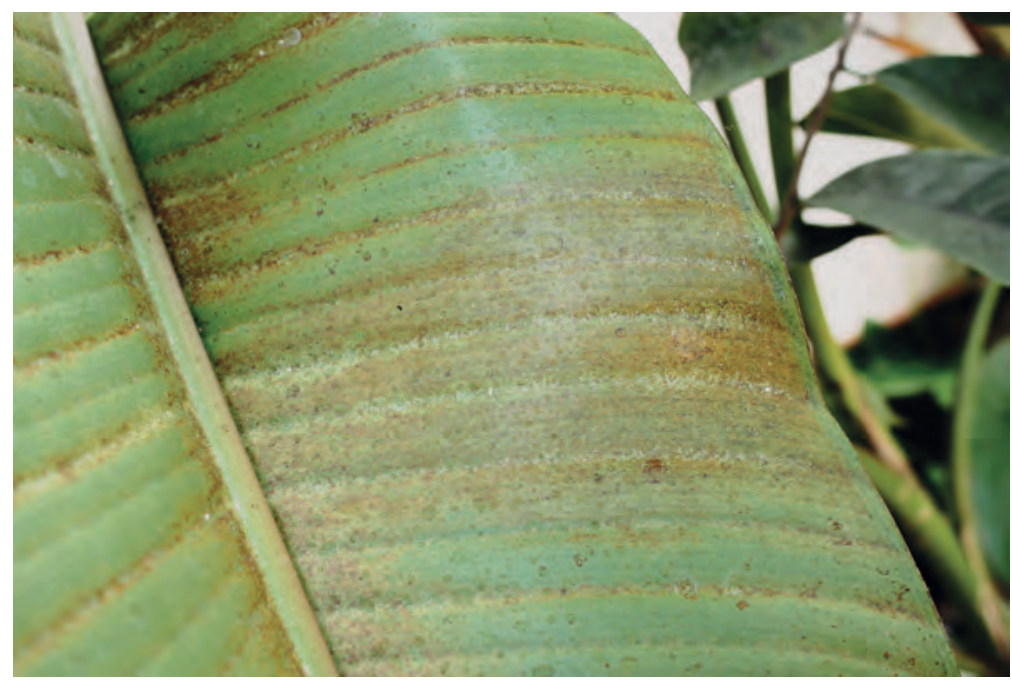

Figura 12 Bronceado provocado por Tetranychus urticae en follaje de Musa velutina: superficie abaxial.

\section{Familia Tarsonemidae}

\section{Polyphagotarsonemus latus (Banks) en uchuva (Physalis peruviana L.)}

La uchuva es un cultivo que ha ido tomando auge en las áreas más altas del país y va ganando interés por parte del consumidor. El material que se siembra en Costa Rica fue traído desde Perú u otro país de Suramérica, entre 1991 y 1992. Las condiciones de clima encontradas en Costa Rica fueron propicias para que este cultivo se extendiera rápidamente y así, hoy en día, es explotado por numerosos productores, especialmente en las partes altas del Valle Central (A. Brenes. 2018. Laboratorio de Biotecnología, CIA. Comunicación personal).
Los daños provocados por esta especie se observan notablemente en el pedúnculo y cáliz de los frutos, en donde se aprecia un bronceado (Figura 13A) en ciertas áreas. Allí se localizan los ácaros, así como sus posturas (Figuras 13B, 13C, 13D). Asimismo, como es característico en ácaros tarsonémidos, sus ataques se producen en los brotes de la planta que generan deformaciones de los mismos (De Moraes y Flechtmann 2008). Estos son coincidentes con los síntomas observados en otras plantas hospedantes que son comúnmente atacados por ácaros tarsonémidos (Figura 13E). Cuando las plantas crecen, el follaje permanece con la deformación, como consecuencia del daño ocurrido cuando los ácaros atacaron los brotes. 

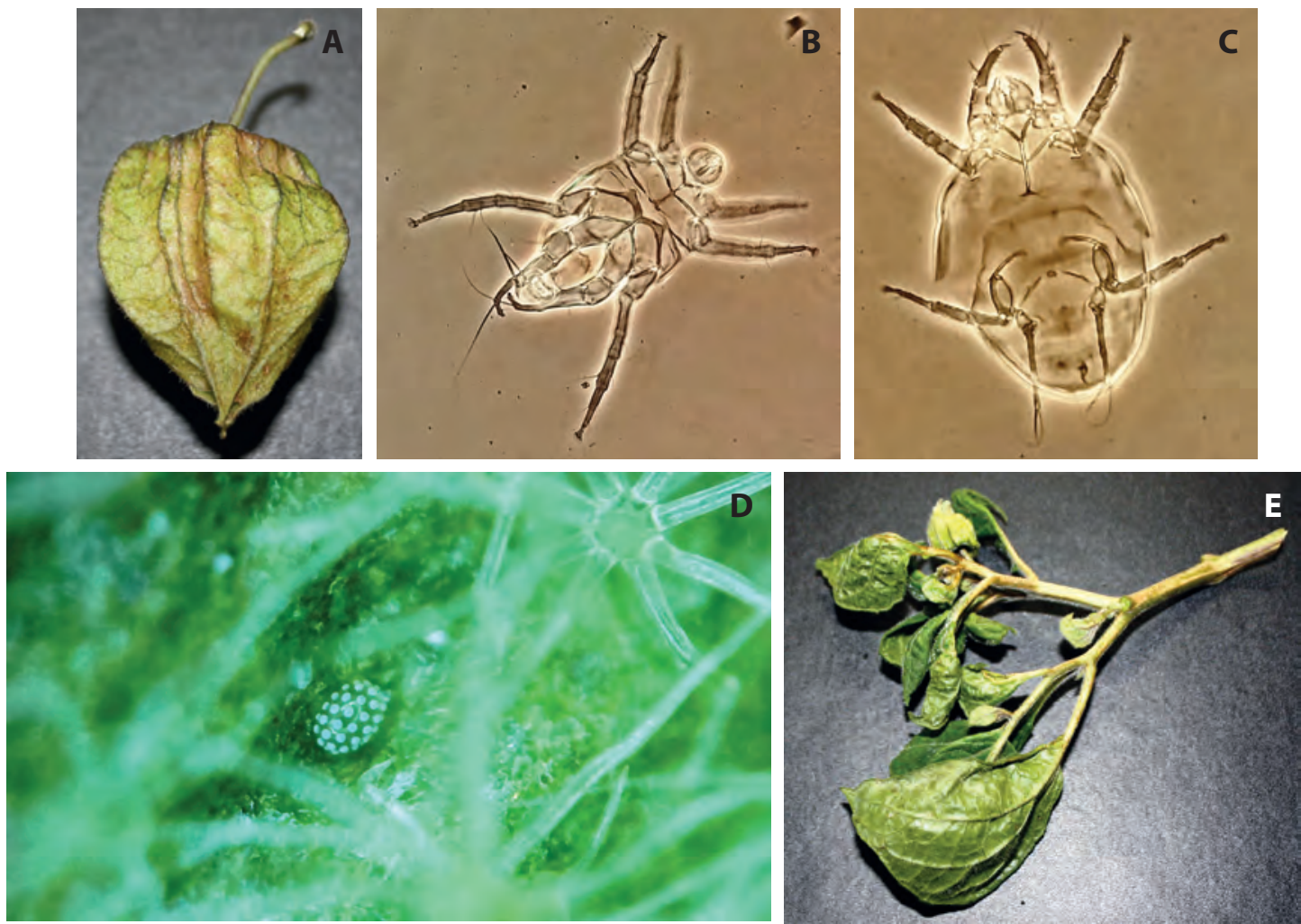

Figura 13 A) Bronceado en cáliz de fruto de Physalis peruviana provocado por Polyphagotarsonemus latus, B) Macho de P. latus asociado con P. peruviana, C) Hembra de P. latus asociada con P. peruviana, D) Huevo de P. latus depositado en follaje de $P$. peruviana, E) Deformación de brotes provocado por $P$. latus en $P$. peruviana.

\section{AGRADECIMIENTOS}

Al Dr. Ronald Ochoa, por la confirmación de algunos de los especímenes de Acari incluidos en esta publicación.

Al Dr. Carlos Morales, por la identificación de varias de las plantas hospedantes, en donde se recolectaron los ácaros.

A la Dra. Mónica Blanco, y al Dr. Javier Monge, por la revisión del manuscrito y valiosas sugerencias aportadas.

\section{LITERATURA CITADA}

Aguilar, H; González, ML; Vargas, C; Ochoa, R. 1990. Tuckerella knorri Baker y Tuttle, agente causal del resquebrajamiento del fruto de los cítricos. Boletín Informativo MIP (Costa Rica) $\mathrm{N}^{\circ} \cdot 18: 1-3$

Aguilar, H; Murillo, P. 2008. Nuevos hospederos y registros de ácaros fitófagos para Costa Rica: período 20022008. Agronomía Costarricense 32(2):7-28.

Aguilar, H; Murillo, P. 2012. Nuevos hospederos y registros de ácaros fitófagos para Costa Rica: período 20082012. Agronomía Costarricense 36(2):11-28.

Amrine Junior, JW; Stasny, TA. 1994. Catalog of the Eriophyoidea (Acarina: Prostigmata) of the World. West Bloomfield, Michigan, Estados Unidos de América, Indira Publishing House. 798 p.

Baker, EW; Tuttle, DM. 1994. A guide to the spider mites (Tetranychidae) of the United States. West Bloomfield, Michigan, Estados Unidos de América. Indira Publishing House. 347 p.

Beard, JJ; Walter, DE. 2005. New species of Tuckerella (Prostigmata: Tetranychoidea: Tuckerellidae) from Australia with descriptions of all stages and 
discussion of the tritonymphal stage. Acarologia 45(1):49-60.

Beard, JJ; Ochoa, R; Bauchan, GR; Trice, M; Redford, AJ; Walters, TW, Mitter, C. 2012. Flat Mites of the World. Identification Technology Program, CPHST, PPQ, APHIS, USDA (en línea). Fort Collins, Colorado, Estados Unidos de América. Consultado 28 oct. 2018. Disponible en https://www.invasive. org/browse/autsubs.cfm?aut=125546

Beard, JJ; Ochoa, R; Childers, CC; Bauchan, GR; Shepard, M. 2013. Travelling with tea: a Tuckerella's tale. Experimental and Applied Acarology 59:177-202.

Beard, JJ; Ochoa, R; Braswell, WE; Bauchan, GR. 2015. Brevipalpus phoenicis (Geijskes) species complex (Acari: Tenuipalpidae)-a closer look. Zootaxa 3944(1):001-067.

De Lillo, E; Craemer, C; Amrine Junior, JW; Nuzzaci, G. 2010. Recommended procedures and techniques for morphological studies of Eriophyoidea (Acari: Prostigmata). Experimental and Applied Acarology 51:283-307.

De Moraes, GJ; Flechtmann, CHW. 2008. Manual de Acarologia. Acarologia Básica e Ácaros de Plantas Cultivadas no Brasil. São Paulo, Brasil, Holos, Editora. $288 \mathrm{p}$.

Freitez, FP. 1974. Reconocimiento preliminar de ácaros fitoparásitos de la familia Tetranychidae de Costa Rica (Acarina). Tesis Lic. San José, Costa Rica, Universidad de Costa Rica. 145 p.

Gerson, U. 1985. Ecology: Webbing. In Helle, W; Sabelis, MW (eds.). Spider mites their biology, natural enemies and control., Amsterdam, The Netherlands, Elsevier Science Publisher. p. 223-232.

Gutierrez, J. 1985. Anatomy, Phylogeny and Systematics. In Helle, W; Sabelis, MW (eds.). Spider mites their biology, natural enemies and control., Amsterdam, The Netherlands, Elsevier Science Publisher. p. 75-90.

Jeppson, LR; Keifer, HH; Baker, EW. 1975. Mites injurious to economic plants. Berkeley, California, Estados Unidos de América. University of California Press. 648 p.

Keifer, HH; Baker, EW; Kono, T; Delfinado, M; Styer, WE. 1982. An illustrated guide to plant abnormalities caused by eriophyid mites in North America. Agriculture Handbook $N^{\circ}$. 573. Estados Unidos de América, U.S. Department of Agriculture. 178 p.

Krantz, GW; Walter, DE. 2009. A manual of acarology. 3 ed. Lubbock, Estados Unidos de América,Texas Tech. University Press. $807 \mathrm{p}$.

Lindquist, EE. 1986. The world genera of Tarsonemidae (Acari: Heterostigmata): a morphological, phylogenetic, and systematic revision, with a reclassification of family group taxa in the
Heterostigmata. The Memoirs of the Entomological Society of Canada 118(supl.136):1-517.

Mesa, NC; Ochoa, R; Welbourn, WC; Evans, GA; De Moraes, GJ. 2009. A catalog of the Tenuipalpidae (Acari) of the World with a key to genera. Zootaxa 2098:1-185.

Meyer, MKP (Smith); Ueckermann, EA. 1997. A review of some species of the families Allochaetophoridae, Linotetranidae and Tuckerellidae (Acari: Tetranychoidea). International Journal of Acarology 23(2):67-92.

Migeon, A; Dorkeld, F. 2018. Spider Mites Web: a comprehensive database for the Tetranychidae (en línea). Montpellier, Francia. Consultado 20 nov. 2018. Disponible en: http://wwwl.montpellier.inra. $\mathrm{fr} / \mathrm{CBGP} /$ spmweb/

Navia, D; Ferreira, CBS; Reis, AC; Gondim, MGC. 2015. Traditional and geometric morphometrics supporting the differentiation of two new Retracrus (Phytoptidae) species associated with heliconias. Experimental and Applied Acarology 67(1):87-121.

Ochoa, R. 1989. The genus Tuckerella in Costa Rica (Acari: Tuckerellidae). International Journal of Acarology 15(4):205-207.

Ochoa, R; Salas, LA. 1989. The genus Brevipalpus in Costa Rica (Acari: Tenuipalpidae). International Journal of Acarology 15(1):21-30.

Ochoa, R; Aguilar, H; Vargas, C. 1991. Ácaros fitófagos de América Central. Turrialba, Costa Rica, CATIE. $251 \mathrm{p}$.

Ochoa, R; Aguilar H; Vargas, C. 1994. Phytophagous mites of Central America. Turrialba, Costa Rica, CATIE. $234 \mathrm{p}$.

Ochoa, R; Smiley, RL; Saunders, JL. 1991. The family Tarsonemidae in Costa Rica (Acari: Heterostigmata). International Journal of Acarology 17(1):41-86.

Pritchard, AE; Baker, EW. 1955. A revision of the spider mite family Tetranychidae. San Francisco, California, Estados Unidos de América. 472 p. (Pacific Coast Entomological Society, v. 2).

Pritchard, AE; Baker, EW. 1958. The false spider mites Acarina (Tenuipalpidae). University of California Publications in Entomology 14(3):175-274.

Salas, LA. 1978. Algunas notas sobre las arañitas rojas (Acari: Tetranychidae) halladas en Costa Rica. Agronomía Costarricense 2(1):47-59.

Seeman, OD; Beard, JJ. 2011. Identification of exotic pest and Australian native and naturalised species of Tetranychus (Acari: Tetranychidae). Zootaxa 2961:1-72.

Tuttle, DM; Baker, EW; Abbatiello, MJ. 1976. Spider mites of Mexico (Acari: Tetranychidae). International Journal of Acarology 2(2):1-108. 